\title{
PERANAN PERPUSTAKAAN DALAM MENINGKATKAN BUDAYA GEMAR MEMBACA MAHASISWA PADA PROGRAM STUDI ILMU ADMINISTRASI NEGARA \\ FAKULTAS ILMU SOSIAL DAN ILMU POLITIK UNIVERSITAS SANG BUMI RUWA JURAI
}

\section{The Role of Library in Improving Students' Reading Culture in State Administrative Science Study Program \\ Faculty of Social Science and Political Science Sang Bumi Ruwa Jurai University}

\author{
Eka Ubaya Taruna Rauf \\ Fakultas Ilmu Sosial Dan Ilmu Politik, Universitas Sang Bumi Ruwa Jurai \\ ekaubaya77@gmail.com
}

\begin{abstract}
This study entitled The Role of Libraries in Improving the Reading Culture of Students in the State Administration Study Program, Faculty of Social and Political Sciences, Sang Bumi Ruwa Jurai University aims to determine the role of libraries which consists of four components, namely librarians, collections, management and spatial management. in improving the reading culture of students in the State Administration Study Program, Faculty of Social and Political Sciences, Sang Bumi Ruwa Jurai University. This research uses a descriptive method. The data collection technique used is by distributing questionnaires, interviews, observations and literature studies. The results of the research can be said that the librarian in the library of the State Administration Study Program, Faculty of Social and Political Sciences, Sang Bumi Ruwa Jurai University has a role in increasing the reading culture of students, collections in the library of the State Administration Study Program, Faculty of Social and Political Sciences, Sang Bumi University. Ruwa Jurai has a role in increasing students' reading culture, library management in the library of the State Administration Science Study Program, Faculty of Social and Political Sciences, Sang Bumi University. Ruwa Jurai has a role in increasing students' reading habit, and the layout of the library in the Administrative Sciences Study Program library. The State Faculty of Social and Political Sciences, University of Sang Bumi Ruwa Jurai has a role in increasing the reading culture of students.
\end{abstract}

Keywords: library, culture, love to read

\begin{abstract}
ABSTRAK
Penelitian ini berjudul Peranan Perpustakaan Dalam Meningkatkan Budaya Gemar Membaca Mahasiswa Pada Program Studi Ilmu Administrasi Negara Fakultas Ilmu Sosial Dan Ilmu Politik Universitas Sang Bumi Ruwa Jurai ini bertujuan untuk mengetahui peran perpustakaan yang terdiri dari empat komponen, yaitu pustakawan, koleksi, manajemen pengelolaan dan tata ruang dalam meningkatkan budaya gemar membaca Mahasiswa Pada Program Studi Ilmu Administrasi Negara Fakultas Ilmu Sosial Dan Ilmu Politik Universitas Sang Bumi Ruwa Jurai. Penelitian ini menggunakan metode deskriptif. Teknik pengumpulan data yang dilakukan adalah dengan cara menyebar angket, wawancara, observasi dan studi literatur. Hasil penelitian dapat dikatakan bahwa pustakawan di perpustakaan Program Studi Ilmu Administrasi Negara Fakultas Ilmu Sosial Dan Ilmu Politik Universitas Sang Bumi Ruwa Jurai mempunyai peran dalam meningkatkan budaya gemar membaca mahasiswa, koleksi di perpustakaan Program Studi Ilmu Administrasi Negara Fakultas Ilmu Sosial Dan Ilmu Politik Universitas Sang Bumi
\end{abstract}


Ruwa Jurai mempunyai peranan dalam meningkatkan budaya gemar membaca mahasiswa, pengelolaan perpustakaan di perpustakaan Program Studi Ilmu Administrasi Negara Fakultas Ilmu Sosial Dan Ilmu Politik Universitas Sang Bumi Ruwa Jurai mempunyai peranan dalam meningkatkan budaya gemar membaca mahasiswa, dan tata ruang perpustakaan di perpustakaan Program Studi Ilmu Administrasi Negara Fakultas Ilmu Sosial Dan Ilmu Politik Universitas Sang Bumi Ruwa Jurai mempunyai peranan dalam meningkatkan budaya gemar membaca mahasiswa.

Kata kunci: perpustakaan, budaya, gemar membaca

\section{Pendahuluan}

Dalam undang-undang Nomor 25 tahun 2000 tentang Program Pembangunan Nasional (PROPENAS) dijelaskan bahwa: "Perpustakaan merupakan sumber daya pendidikan yang penting dalam upaya meningkatkan kualitas Pendidikan. Dengan adanya undang-undang tersebut diharapkan ada peningkatan kualitas dalam dunia perpustakaan untuk semakin maju dan berkembang sehingga perpustakaan yang mampu melayani segala bentuk kebutuhan informasi yang dibutuhkan pengguna, terutama keberadaan perpustakaan yang ada di setiap lembaga pendidikan pun seyogyanya menjadi bagian yang tidak terpisahkan dengan dunia pendidikan.

Perpustakaan sebagai salah satu pusat informasi, dalam kacamata pendidikan peranannya cukup penting. Karena proses belajar mengajar dapat berjalan dengan efektif jika rujukannya tersedia. Melalui perpustakaan dengan sumber-sumber informasi yang ada didalamnya sedianya dapat membantu untuk meningkatkan mutu kualitas pendidikan dan outputnya kelak.

Dalam kehidupan yang serba modern dan cepat seperti saat ini semua orang membutuhkan informasi sebagai suatu hal yang hakiki. Tanpa informasi atau ketinggalan informasi akan membuat seseorang tersisih dan terbelakang. Peran perpustakaan menjadi nyata. Perpustakaan menjadi pusat informasi yang tidak pernah habisnya untuk digali, ditimba dan dikembangkan. Melalui perpustakaan seseorang dapat bertukar inforrnasi dan saling memperoleh nilai tambah untuk perkembangan zaman.

Jika dikaitkan dengan proses belajar mengajar Pada Program Studi Ilmu Administrasi Negara Fakultas Ilmu Sosial Dan Ilmu Politik Universitas Sang Bumi Ruwa Jurai, perpustakaan di sana memberikan sumbangan yang sangat berharga dalam upayanya meningkatkan minat baca mahasiswa serta meningkatkan kualitas pendidikan dan pengajaran. Perpustakaan dapat memainkan peran, khususnya dalam membantu mahasiswa untuk mencapai tujuan pendidikan. Dengan memanfaatan perpustakaan secara maksimal, mahasiswa diharapkan terbiasa dengan aktifitas membaca, memahami pelajaran, mengerti maksud dari sebuah informasi dan ilmu pengetahuan, serta menghasilkan karya bermutu. Kebiasaan membaca buku yang dilakukan oleh mahasiswa, akan meningkatkan pola pikirnya sehingga perlu dijadikan aktivitas kegiatan sehari-hari.

Perpustakaan Program Studi Ilmu Administrasi Negara Fakultas Ilmu Sosial Dan Ilmu Politik Universitas Sang Bumi Ruwa Jurai dapat dijadikan sumber belajar mahasiswa baik dalam proses kegiatan belajar mengajar secara formal maupun non formal untuk membantu Program Studi Ilmu Administrasi Negara Fakultas Ilmu Sosial Dan Ilmu Politik Universitas Sang Bumi Ruwa Jurai dalam upaya mencapai tujuan pendidikan di Program 
Studi Ilmu Administrasi Negara Fakultas Ilmu Sosial Dan Ilmu Politik Universitas Sang Bumi Ruwa Jurai tersebut. Pada kenyataannya, perpustakaan kurang mendapat tempat di lingkungan sendiri. Tidak banyak mahasiswa yang memanfaatkan waktu luang atau jam-jam kosong pelajaran untuk membaca di perpustakaan.

Minat baca menurut Kamus

Besar Bahasa Indonesia (2003: 583) memuat pengertian minat sebagai kecenderungan hati yang tinggi terhadap sesuatu, gairah atau keinginan. Sedangkan menurut Slameto (1995:180) minat adalah suatu rasa lebih suka dan rasa ketertarikan pada suatu hal atau aktifltas, tanpa ada yang menyuruh. Minat pada dasarnya adalah penerimaan akan suatu hubungan antara diri sendiri dengan suatu diluar diri. Semakin kuat atau dekat hubungan tersebut, semakin besar minat.

Pada dasarnya, pihak Program Studi Ilmu Administrasi Negara Fakultas Ilmu Sosial Dan Ilmu Politik Universitas Sang Bumi Ruwa Jurai bertanggung jawab ikut menumbuhkan minat baca bagi mahasiswa, karena dari sanalah sumber kreatifitas mahasiswa akan muncul. Program Studi Ilmu Administrasi Negara Fakultas Ilmu Sosial Dan Ilmu Politik Universitas Sang Bumi Ruwa Jurai harus mengajar mahasiswa berpikir melalui budaya belajar yang menekankan pada memahami materi. Sedangkan perpustakaan menjadi fasilitas yang sangat penting perannya dalam menunjang proses pembelajaran tersebut.

Sebuah perpustakaan yang menarik bagi pengguna, secara tidak langsung itu dapat merangsang mereka untuk berkunjung kembali ke perpustakaan tersebut, sehingga dapat berdampak dapat menghasilkan dan meningkatkan minat baca mahasiswa. Dalam menumbuhkan minat baca dan membuktikan bahwa suatu perpustakaan tidak hanya sekedar tempat membaca tetapi sudah berkembang sebagai tempat mahasiswa mengembangkan kemampuan dan bakatnya, serta adanya kebutuhan akan suatu kesempatan yang mengakomodasi keinginan mahasiswa untuk menunjukkan kemampuan yang telah dilatih dan dikembangkan melalui perpustakaan.

Dalam konteks itulah diyakini bahwa minat baca mempengaruhi proses dan hasil belajar mahasiswa. Tidak banyak yang dapat berharap untuk menghasilkan prestasi belajar yang baik dari seorang mahasiswa yang tidak berminat untuk mempelajari sesuatu. Untuk memenuhi kebutuhan para mahasiswanya dalam pencarian informasi, pihak Program Studi Ilmu Administrasi Negara Fakultas Ilmu Sosial Dan Ilmu Politik Universitas Sang Bumi Ruwa Jurai berusaha untuk membuat perpustakaan yang ideal dengan tujuan untuk meningkatkan minat baca mahasiswanya.

Dari uraian di atas, maka penulis tertarik untuk mengadakan penelitian dengan judul: Peran Perpustakaan dalam Meningkatkan Budaya Gemar Membaca Mahasiswa Pada Program Studi Ilmu Administrasi Negara Fakultas Ilmu Sosial Dan Ilmu Politik Universitas Sang Bumi Ruwa Jurai.

\section{Tinjauan pustaka}

Perpustakaan adalah sebuah ruangan atau gedung yang digunakan untuk menyimpan buku dan terbitan lainnya yang biasanya disimpan menurut tata susunan tertentu yang digunakan pembaca bukan untuk dijual (Sulistyo-Basuki, 1991:3).

Kehadiran perpustakaan bukanlah hal yang baru di kalangan masyarakat. Dimana-mana telah diselenggarakan perpustakaan seperti perguruan tinggi baik negeri maupun swasta. Keberadaan perpustakaan 
adalah untuk menunjang sarana belajar mengajar.

Menurut Darmono (2011:1-2), hakikat perpustakaan adalah pusat atau sumber belajar dan sumber informasi bagi pemakainya. Perpustakaan juga berfungsi sebagai rekreasi untuk menunjang hobi dan imajinasi pengunjung. Perpustakaan juga bermanfaat sebagai pusat penelitian yang berarti perpustakaan sebagai lembaga yang turut menunjang kegiatan riset yang terkait dan tersedia di perpustakaan, dan terakhir adalah fungsi deposit yang berarti fungsi menyimpan dan melestarikan semua karya cetak dan karya rekam. Namun masih sedikit sekali yang memiliki kesadaran akan arti pentingnya membaca, hal ini disebabkan karena beberapa kendala yaitu kurangnya sarana perpustakaan yang berakibat pada rendahnya pertumbuhan minat baca mahasiswa dan dosen yang akhirnya menghambat tumbuh kembangnya pola pikir kritis mahasiswa sebagai model bagi terciptanya kondisi berfikir ilmiah di lingkungan perguruan tinggi (Hermawan, 2003:3).

$\begin{array}{llr} & \text { Perpustakaan } & \text { memiliki } \\ \text { yang sangat } & \text { penting } & \text { untuk } \\ \text { meningkatkan } & \text { minat } & \text { baca }\end{array}$
mahasiswanya. Ada beberapa hal tentang perpustakaan yang dapat mempengaruhi minat baca mahasiswa, pertama, ketika sebuah perpustakaan memiliki koleksi yang lengkap, para pengguna informasi akan merasa puas karena informasi yang mereka cari bisa mereka temukan di perpustakaan tersebut. Ketika mereka merasa puas, tidak menutup kemungkinan para pengguna informasi akan datang lagi dan mencari informasi yang lainnya. Kedua, sumber daya manusia yang mengelola perpustakaan juga memiliki peran besar dalam pengaruh minat baca terhadap para pengguna informasi,

Ketiga, adalah manajemen pengelolaan perpustakaan, namun manajemen ini tergantung bagaimana sumber daya manusia yang mengelolanya. Bagaimana sumber daya manusia memajukan sebuah perpustakaan, bagaimana para pengguna mudah untuk menemukan informasi atau koleksi yang mereka butuhkan itu menjadi manajemen perpustakaan yang berdampak kepada kepuasan para pengguna informasi.

Keempat, adalah tata ruang, dalam hal ini bagaimana perpustakaan memberikan kenyamanan kepada para pengguna informasi untuk membaca dan betah untuk berlama-lama di perpustakaan tersebut

Semua kondisi di atas, tentunya akan menimbulkan minat baca pada mahasiswa, pada dasarnya minat dan kebiasaan membaca merupakan keterampilan yang diperoleh setelah seseorang dilahirkan dan bukan merupakan keterampilan bawaan, melainkan perlu dipupuk, dibina, dan dikembangkan. Minat dan kegemaran membaca tidak dengan sendirinya dimiliki seseorang. Minat baca dapat tumbuh dan berkembang dengan cara berbentuk. Dengan demikian diharapkan dari gemar membaca akan meningkat menjadi memiliki jiwa baca, lalu muncul kebiasaan membaca. Selain itu peningkatan gemar membaca harus didukung oleh jumlah dan mutu kinerja perpustakaan yang harus ditingkatkan (Media Pustakawan, 1996:4).

Lilawati (dalam Sandjaja, 2005) mengartikan minat baca adalah suatu perhatian yang kuat dan mendalam disertai dengan perasaan senang terhadap kegiatan membaca sehingga dapat mengarahkan seseorang untuk membaca dengan kemauannya sendiri. Minat membaca adalah sumber motivasi kuat bagi seseorang untuk menganalisa dan mengingat serta mengevaluasi bacaan yang telah dibacanya, yang merupakan pengalaman belajar menggembirakan dan akan mempangaruhi bentuk serta intensitas 
seseorang dalam mencapai cita-citanya kelak di masa yang akan datang, hal tersebut juga adalah bagian dari pengembangan diri yang harus senantiasa diasah sebab minat baca tidak diperoleh dari lahir.

Fungsi utama perpustakaan adalah untuk membangkitkan dan meningkatkan minat baca siswa yang dilayaninya (pemustaka). Dengan program-program yang dibuatnya, perpustakaan menjadi pelopor dalam menarik minat mahasiswa supaya dekat dengan sumber informasi. Dan pustakawan berperan sebagai agen perubahan untuk menciptakan mahasiswa membaca (reading society) sebagai salah satu pilar utama menuju mahasiswa belajar (learning society). Walaupun kesan yang ada sekarang ini adalah perpustakan dan pustakawan hanya berperan sebagai pelayan saja bagi kebutuhan informasi mahasiswa, sejatinya para pustakawanlah yang mengadakan pelatihan- pelatihan atau berbagai macam program dan juga berinisiatif untuk menulis literatur yang dapat membangkitkan semangat membaca mahasiswa, karena ia setiap hari bergulat dengan sumber informasi, di samping itu juga karena pustakawanlah yang paling dekat dengan para pemustaka

Dengan kata lain para mahasiswa akan memutuskan apakah mereka akan membaca atau tidak setelah mereka merasa nyaman dan puas dengan apa yang ditawarkan oleh perpustakaan yang berakibat timbulnya minat baca pada mahasiswa.

\section{Metode Penelitian}

Dalam penelitian ini, metode penelitian yang digunakan adalah deskriptif. Metode deskriptif adalah metode penelitian yang bertujuan untuk menggambarkan suatu keadaan yang sementara berjalan pada saat penelitian dilakukan dengan mengambil sampel dari suatu populasi dan menggunakan kuisioner sebagai alat pengumpulan data pokok. Dengan metode deskriptif ini, diharapkan akan mendapatkan gambaran yang tepat mengenai peran perpustakaan dalam meningkatkan budaya gemar membaca mahasiswa. Sedangkan untuk menggambarkan yang diteliti, digunakan dua jenis data yakni data primer dan data sekunder. Data primer bersumber langsung dari responden penelitian dari pihak-pihak yang relevan, sedangkan data sekunder bersumber pada dokumentasi serta referensi-referensi yarg relevan.

Teknik analisis data penelitian yang digunakan dalam penelitian ini adalah satistik deskriptif. Analisis ini digunkan untuk mendeskripsikan dan menggambarkan data yang terkumpul untuk umum atau generalisasi (Sugiyono, 2012:172). Teknik ini memaparkan jawaban responden dalam bentuk tabel frekuensi den presentase. Tabel-tabel tersebut selanjutnya disertai interpretasi penulis untuk mengetahui makna dari data-data penelitian tersebut. Perhitungan presentase dalam tabel frekuensi dihitung berdasarkan rumus: $\mathrm{P}=\mathrm{f} / \mathrm{n} \times 100 \%$, di mana $\mathrm{P}=$ Presentase frekuensi, $\mathrm{f}=$ Frekuensi kelas dan $\mathrm{n}=$ Ukuran sampel. Lokasi penelitian ini dilakukan di perpustakaan Program Studi Ilmu Administrasi Negara Fakultas Ilmu Sosial Dan Ilmu Politik Universitas Sang Bumi Ruwa Jurai.

\section{Hasil dan Pembahasan}

Dari hasil penelitian yang telah dilakukan, mengenai Peran Perpustakaan dalam Meningkatkan Budaya Gemar Membaca Mahasiswa Program Studi Ilmu Administrasi Negara Fakultas Ilmu Sosial Dan Ilmu Politik Universitas Sang Bumi Ruwa Jurai, dapat diketahui sebagai berikut:

1) Berdasarkan hasil penelitian, dapat diketahui bahwa Pustakawan mempunyai peran di perpustakaan Program Studi Ilmu Administrasi 
Negara Fakultas Ilmu Sosial Dan Ilmu Politik Universitas Sang Bumi Ruwa Jurai dalam meningkatkan budaya gemar membaca mahasiswa. Hal ini terlihat dari jawaban responden yang menyatakan setuju bahkan sangat setuju bahwa pengelola perpustakaan Program Studi Ilmu Administrasi Negara Fakultas Ilmu Sosial Dan Ilmu Politik Universitas Sang Bumi Ruwa Jurai selalu memberikan senyum dalam melayani penggunanya, selain itu pengelola perpustakaan juga selalu bernampilan menarik dan rapih, membantu pengguna jika mengalami kesulitan saat mencari buku, memberikan informasi dengan akurat, menguasai pengetahuan yang luas yang menunjang dalam memberikan pelayanan kepada pengguna, Selain itu, pengelola perpustakaan Program Studi Ilmu Administrasi Negara Fakultas Ilmu Sosial Dan Ilmu Politik Universitas Sang Bumi Ruwa Jurai juga selalu berinisiatif membantu para pengguna informasi.

2) Berdasarkan hasil penelitian, dapat diketahui bahwa koleksi di perpustakaan Program Studi Ilmu Administrasi Negara Fakultas Ilmu Sosial Dan Ilmu Politik Universitas Sang Bumi Ruwa Jurai mempunyai peranan dalam meningkatkan budaya gemar membaca mahasiswa. Hal ini terlihat dari koleksi buku yang terdapat di perpustakaan Program Studi Ilmu Administrasi Negara Fakultas Ilmu Sosial Dan Ilmu Politik Universitas Sang Bumi Ruwa Jurai sesuai dengan kebutuhan mahasiswa; perpustakaan Program Studi Ilmu Administrasi Negara Fakultas Ilmu Sosial Dan Ilmu Politik Universitas Sang Bumi Ruwa Jurai menyediakan buku atau koleksi terbatas, Perpustakaan Program Studi Ilmu Administrasi Negara Fakultas Ilmu Sosial Dan Ilmu Politik Universitas Sang Bumi Ruwa Jurai menyediakan bukubuku terbaru (up to date), para responden mendapatkan pengetahuan yang baru, Perpustakaan Program Studi Ilmu Administrasi Negara Fakultas Ilmu Sosial Dan Ilmu Politik Universitas Sang Bumi Ruwa Jurai tidak menyediakan koleksi yang berbentuk elektronik (seperti: audio, visual, dan audio visual) namun mereka menyediakna komputer sebagai sarana penggantinya. Selain buku, perpustakaan Program Studi Ilmu Administrasi Negara Fakultas Ilmu Sosial Dan Ilmu Politik Universitas Sang Bumi Ruwa Jurai menyediakan koleksi berbentuk cetak lainnya (seperti majalah, novel, koran).

3) Berdasarkan hasil penelitian, dapat diketahui bahwa pengelolaan perpustakaan di perpustakaan Program Studi Ilmu Administrasi Negara Fakultas Ilmu Sosial Dan Ilmu Politik Universitas Sang Bumi Ruwa Jurai mempunyai peranan dalam meningkatkan budaya gemar membaca mahasiswa. Hal ini berdasarkan bahwa, perpustakaan Program Studi Ilmu Administrasi Negara Fakultas Ilmu Sosial Dan Ilmu Politik Universitas Sang Bumi Ruwa Jurai mengadakan kegiatan yang menarik tiap tahunnya dan perpustakaan Program Studi Ilmu Administrasi Negara Fakultas Ilmu Sosial Dan Ilmu Politik Universitas Sang Bumi Ruwa Jurai konsisten menyelenggarakan kegiatan setiap tahunnya.

4) Berdasarkan hasil penelitian, dapat diketahui bahwa tata ruang 
perpustakaan di perpustakaan Program Studi Ilmu Administrasi Negara Fakultas Ilmu Sosial Dan Ilmu Politik Universitas Sang Bumi Ruwa Jurai mempunyai peranan dalam meningkatkan budaya gemar membaca mahasiswa. Hal ini dapat dilihat dari ruang perpustakaan Program Studi Ilmu Administrasi Negara Fakultas Ilmu Sosial Dan Ilmu Politik Universitas Sang Bumi Ruwa Jurai berada pada posisi yang strategis, mempunyai ventilasi udara yang baik, pengguna mendapatkan kenyamanan saat berada di ruang baca, pengguna mendapatkan kenyamanan saat berada di ruang sirkulasi, pengguna mendapatkan kenyamanan saat berada di ruang komputer, perpustakaan Program Studi Ilmu Administrasi Negara Fakultas Ilmu Sosial Dan Ilmu Politik Universitas Sang Bumi Ruwa Jurai mempunyai penerangan (lampu) yang baik, dan walaupun perpustakaan Program Studi Ilmu Administrasi Negara Fakultas Ilmu Sosial Dan Ilmu Politik Universitas Sang Bumi Ruwa Jurai tidak dapat menampung banyak pengunjung.

\section{Kesimpulan}

Berdasarkan pembahasan yang telah dipaparkan di atas, dapat disimpulkan sebagai berikut:

1. Perpustakaan Program Studi Ilmu Administrasi Negara Fakultas Ilmu Sosial Dan Ilmu Politik Universitas Sang Bumi Ruwa Jurai menyediakan koleksi buku yang lebih up to date (cetakan terbaru dan tahun terbit yang aktual), sehingga koleksi yang dimiliki perpustakaan Program Studi Ilmu Administrasi Negara Fakultas Ilmu Sosial Dan Ilmu Politik Universitas Sang Bumi Ruwa Jurai selain beragam, juga sesuai/relevan dengan kebutuhan informasi mahasiswa;

2. Perpustakaan menambah koleksi buku terutama buku-buku umum jenis karya fiksi dan juga menyediakan koleksi audio visual dengan terbaru;

3. Perpustakaan Program Studi Ilmu Administrasi Negara Fakultas Ilmu Sosial Dan Ilmu Politik Universitas Sang Bumi Ruwa Jurai sebaiknya lebih meningkatkan kualitas sarana dan prasarana berbasis teknologi yang lebih lengkap dan mutakhir, yaitu menambah kecepatan akses internet dan pengalihan proses penelusuran bahan pustaka manual ke bentuk digital (komputerisasi), agar mempermudah mahasiswa mengakses informasi;

4. Mahasiswa menilai staf perpustakaan memiliki pengetahuan dan wawasan yang cukup luas, tetapi mahasiswa merasa belum mengenal betul staf perpustakaan. Untuk itu sebaiknya staf lebih banyak berinteraksi dengan mahasiswa melalui komunikasi secara aktif untuk membantu mahasiswa memperoleh informasi yang dibutuhkan.

\section{DAFTAR PUSTAKA}

Darmono, (2011). Manajemen dan Tata Kerja Perpustakaan Perguruan Tinggi. PT. Grasindo, Jakarta.

Departemen Pendidikan Nasional, Pusat Bahasa. (2003). Kamus Bahasa Indonesia. Jakarta.

Departemen Pendidikan Nasional RI. (2005). Pedoman Perpustakaan Perguruan Tinggi, Jakarta: Departemen Pendidikan Nasional RI Direktorat Jendral Pendidikan Tinggi. 
Hermawan, Iwan. (2003). "Potret Perpustakaan Dewasa Ini", Berita Pikiran Rakyat On-Line, 15 November (2020), h.3. Media Pustakawan, 1996.

Qalyuby, Shihabuddin (ed.), (2003). Dasar-dasar Ilmu Perpustakaan dan Informasi. Sinar Grafika Inodnesia Jakarta

Rakhmat, Jalaluddin. (2001). Psikologi Komunikasi. PT. Remaja Rosdakarya. Bandung.

Singarimbun, Masri. (1989). Metode Penelitian Survai. Jakarta: LPS3ES

Sandjaja, B., dan Heriyanto. A., (2006). Panduan Penelitian, Prestasi Pustaka. Jakarta

Slameto. (1995). Belajar dan faktorfaktor Yang Mempengaruhinya, PT. Rineka Cipta. Jakarta.

Sugiyono, (2012), Metode Penelitian Kuantitatif, Kualitatif dan $R \& D$, Alfabeta, Bandung

Sulistyo-Basuki, (1991). Pengantar Ilmu Perpustakaan Gramedia Pustaka Utama Jakarta

Undang-undang No. 20 tahun (2003), tentang Sistem Pendidikan Nasional (http://pcucamel.petra.ac.id/dow nloadf ile.php?id=89, diakses tanggal, 15 November 2020)

Wahyudiati. "Optimalisasi Perpustakaan Perguruan Tinggi Untuk Menumbuhkan Minat Baca Mahasiswa". Artikel ini diakses tanggal 15 November 2020 melalui situs 